\title{
Simultaneous isolation of cellulose and lignin from wheat straw and catalytic conversion to valuable chemical products
}

\author{
Bowei Yu, Guozhi Fan* (i), Sijiu Zhao, Yuchan Lu, Qiao He, Qunpeng Cheng, Juntao Yan, Bo Chai \\ and Guangsen Song
}

\begin{abstract}
Convertible cellulose and lignin were simultaneously isolated from wheat straw using a two-stage process via simply varying temperature and $\mathrm{H}_{2} \mathrm{SO}_{4}$ concentration. At the first-stage, cellulose was obtained by pretreating wheat straw at lower temperature and acid concentration using an organosolv process. The purity, yield and recovery rate of cellulose reached $86.8 \mathrm{wt} \%, 55.2$ and $92.8 \%$ at $150{ }^{\circ} \mathrm{C}$ with $1 \mathrm{wt} \% \mathrm{H}_{2} \mathrm{SO}_{4}$. At the second stage, the residual liquid was further treated at higher temperature and acid concentration, giving $17.4 \%$ lignin yield with $86.6 \%$ recovery rate and $93.2 \mathrm{wt} \%$ purity at $180^{\circ} \mathrm{C}$ with $1.5 \mathrm{wt} \% \mathrm{H}_{2} \mathrm{SO}_{4}$. The conversion of the as-isolated cellulose and lignin into chemicals was further investigated. The total yield of 5-hydroxymethylfurfural and glucose derived from wheat straw cellulose reached $82.5 \%$, and $18.3 \%$ yield of monophenolic compounds from lignin were obtained, respectively. These results indicated that the two-stage process was effective for obtaining high-quality cellulose and lignin from wheat straw. Both of them displayed excellent convertible property.
\end{abstract}

Keywords: Wheat straw, Two-stage process, Isolation, Cellulose, Lignin, Conversion

\section{Introduction}

Fossil fuels are increasingly being consumed at a very rapid rate because of overexploitation resulting from industry development and population growth. Lignocellulosic biomass is considered a promising alternative for traditional fossil fuels and a sustainable feedstock due to its availability and low cost. Lignocellulosic biomass is primarily composed of cellulose, hemicellulose, lignin and a small amount of ash (mainly comprising silica) [1]. Among them, cellulose and lignin are potential resources for fuel and chemicals production.

Cellulose is simply composed of glucose units via $\beta-1,4-$ glucosidic bonds [2]. Generally, cellulose hydrolysis leads to the production of fermentable sugars and liquid fuels. The conversion of cellulose into various derivatives such as

\footnotetext{
*Correspondence: fgzcch@whpu.edu.cn

School of Chemical and Environmental Engineering, Wuhan Polytechnic University, Wuhan 430023, China
}

glucose [3], 5-hydroxymethylfurfural (HMF) [4], alcohol [5], levoglucosan [6], cellulose nanocrystals [7], methylcellulose and cellulose acetate [8] is a rapidly expanding research area in the past few years. Lignin, often forms $10-25 \mathrm{wt} \%$ of lignocellulosic biomass, is the second-most abundant natural biopolymer in the world. It is composed of three primary units including coniferyl (3-methoxy4-hydroxycinnamyl), sinapyl (3,5-dimethoxy-4-hydroxycinnamyl) and $p$-coumaryl (4-hydroxycinnamyl) alcohols, which are primarily linked by $\beta-\mathrm{O}-4$ and $\mathrm{C}-\mathrm{C}$ bonds [9]. These monolignols produce $p$-hydroxyphenyl $(\mathrm{H})$, guaiacyl $(G)$ and syringyl (S) units when they are incorporated into lignin polymer. The degradation of lignin into small molecular compounds supplies an alternative raw material for producing aromatic compounds including syringaldehyde, vanillin, $p$-hydroxybenzaldehyde, acetosyringone, acetovanillone, syringic acid and vanillic acid [5] because of its unique structure and chemical properties.

The isolation of lignocellulose material into its primary constituents is a key operation for obtaining convertible 
cellulose and lignin [10]. The high-purity cellulose and lignin isolated from lignocellulose could be further converted into chemicals. The former could be converted into cellulose nanocrystals [8], glucose [11], cellulose acetate [12] and HMF [4], and the latter could be converted to phenolic monomers via catalytic oxidation [13]. The isolation of cellulose and lignin from lignocellulosic biomass has attracted considerable attention as the shortage of fossil resources becomes more and more serious [14].

Treating lignocellulosic biomass to obtain individual components is usually divided into three categories: biological, physical and chemical processes. Steam explosion, autohydrolysis, chemical treatment (including organosolv fractionation and alkali-acid process), combined chemical and enzymatic extraction have been developed [9, 15-17]. Among them, chemical treatment is particularly effective for isolating cellulose and/or lignin due to the hydrolysis of hemicellulose and/or cellulose in the presence of acid catalyst [18], which destroys the interaction between components and thus promoting the separation of components. Supercritical extraction [19], enzymatic hydrolysis [10], ethanol and 1,4-dioxane based extraction process [20] have also been successfully developed to isolate lignin from lignocellulosic biomass such as hardwood, miscanthus and straw. Organosolv fractionation is extensively used to separate these main components because it aims to fractionate lignocellulosic biomass into its natural structure as much as possible [21]. Two-stage method was also developed to separate the main components from lignocellulose. A two-stage pretreatment using acidic dioxane followed by dilute hydrochloric acid on sugar production from corn stover was reported [22, 23]. However, poor lignin recovery at $50 \%$ was given. In addition, the first step and the second step were generally carried out in different reaction media, which led to complicated process. For example, the first step was performed in $\mathrm{NaOH}$ solution while the second step was in $\mathrm{H}_{2} \mathrm{SO}_{4}$ solution [24].

In summary, there are still some defects in the current separation methods. Most works were focused on obtaining only one high-purity component such as cellulose, hemicellulose or lignin while the purity and/or recovery of other components was not taken into account. It leads to low utilization rate of lignocellulose resource. Therefore, the development of efficient-simultaneous separation of high-quality cellulose and lignin is of great significance, which is undoubtedly beneficial to improve high-valued utilization of lignocellulose.

Straw is one of the most abundant and low-cost biomasses available in the world. It is considered a potential alternative for fossil fuels and chemical resource [25]. In this work, wheat straw was applied to obtain convertible cellulose and lignin because of its availability and high content of cellulose and lignin. The simultaneously isolating for high-quality of cellulose and lignin was performed by a two-stage process. Cellulose was separated from hemicellulose and lignin at lower temperature and acid concentration at the first-stage. Subsequently, the residual liquid including most lignin and small amount of hemicellulose were further treated at the second-stage by increasing temperature and acid concentration. The conversion of the as-isolated cellulose and lignin into HMF, glucose and monophenolic compounds was also investigated.

\section{Materials and methods \\ Materials}

Wheat straw was supplied by a local farm located in Wuhan city (Hubei, China). Cellulose (average particle size of $90 \mu \mathrm{m}$ ) and HMF (purity of 99\%) were of reagent grade and purchased from Sigma. Dealkaline lignin was purchased from J \& $\mathrm{K}$ chemical. Other reagents were commercially supplied by Sinopharm Chemical Reagent Co., Ltd and used without further purification. Straw was extracted in mixing toluene/ethanol to remove soluble impurity according to the reported procedure [26], and the extracted sample was denoted as extracted wheat straw (EWS).

\section{Isolation of cellulose and lignin from wheat straw via a two-step process Isolation of cellulose at the first step}

Typically, $15 \mathrm{~g}$ EWS, $150 \mathrm{~mL}$ mixture of 1,4-dioxane and $\mathrm{H}_{2} \mathrm{O}(2: 1, \mathrm{v} / \mathrm{v})$ and $\mathrm{H}_{2} \mathrm{SO}_{4}$ were added into a $500 \mathrm{~mL}$ stainless steel autoclave. The mixture was heated at $150{ }^{\circ} \mathrm{C}$ for $6 \mathrm{~h}$ with $1.0 \mathrm{wt} \% \mathrm{H}_{2} \mathrm{SO}_{4}$ under magnetic stirring. The solid was then collected by filtration and thoroughly washed using $30 \mathrm{~mL}$ mixture of 1,4-dioxane and $\mathrm{H}_{2} \mathrm{O}(2: 1, \mathrm{v} / \mathrm{v})$ thrice. The solid was freeze-dried for $12 \mathrm{~h}$, thus yielding wheat straw cellulose.

\section{Isolation of lignin at the second step}

After the first step, the filtrate and washes (residual liquid) were also collected and combined before adding $\mathrm{H}_{2} \mathrm{SO}_{4}$ until the concentration reached $1.5 \mathrm{wt} \%$. The mixture was then heated at $180{ }^{\circ} \mathrm{C}$ for $1.5 \mathrm{~h}$ under stirring. After cooling to room temperature, the mixture was transferred into a $1000 \mathrm{~mL}$ beaker and $540 \mathrm{~mL} \mathrm{H}_{2} \mathrm{O}$ were added. Lignin was then precipitated and collected via centrifugation, followed by freeze-drying for $10 \mathrm{~h}$.

\section{Conversion of cellulose and lignin isolated from wheat straw} Conversion of cellulose isolated from wheat straw

The conversion of cellulose was performed according to our previous work [4]. In a typical procedure, $0.5 \mathrm{~g}$ 
cellulose, $0.5 \mathrm{~g}$ phosphotungstic acid and $10 \mathrm{~mL}$ tetrahydrofuran were added into a $50 \mathrm{ml}$ stainless steel autoclave. The autoclave was sealed and the air in it was flushed with $1 \mathrm{MPa}$ nitrogen three times. Then $1 \mathrm{MPa}$ nitrogen was introduced and the mixture was heated to $190^{\circ} \mathrm{C}$ for $6 \mathrm{~h}$. After cooling to room temperature, $10 \mathrm{~mL}$ $\mathrm{N}, \mathrm{N}$-dimethylformamide was added to the autoclave and the mixture was subsequently kept at $130{ }^{\circ} \mathrm{C}$ for $4 \mathrm{~h}$ under nitrogen atmosphere. The autoclave was cooled to room temperature and the pressure in it was gradually released. Solid residues were collected by filtration, washed with THF and the washes were combined with filtrate. The liquid reaction mixture was then centrifuged and quantitatively analyzed by gas chromatography (GC) and 3,5-dinitrosalicylic acid (DNS) method.

\section{Oxidative conversion of lignin isolated from wheat straw}

Typically, $1 \mathrm{~g}$ lignin in $50 \mathrm{~mL} 1 \mathrm{~mol} / \mathrm{L} \mathrm{NaOH}$ aqueous solution was dispersed via ultrasonic vibration before adding to a $500 \mathrm{~mL}$ autoclave. Then $4 \mathrm{~mL}$ nitrobenzene and $4.1 \mathrm{~g} \mathrm{NaAlO}_{2}$ were added. The mixture was then heated at $170{ }^{\circ} \mathrm{C}$ for $2.5 \mathrm{~h}$ under magnetic stirring. The reactor was quickly cooled by placing in an iced water bath for $20 \mathrm{~min} .20 \mathrm{wt} \%$ hydrochloric acid was added into the reaction mixture until the $\mathrm{pH}$ value of 1 followed by extraction using chloroform. Monophenolic compounds in the organic soluble fraction was then quantitatively analyzed by high-performance liquid chromatography (HPLC) and high-performance liquid chromatographymass spectrometry (HPLC-MS).

\section{Determination and calculation}

The contents (purities) of cellulose, hemicellulose, lignin and ash were determined according to the previously reported procedures [27]. The determinations were based on the averages of three replicates. The yields of cellulose and lignin, theoretical yield of lignin and removal rates of components, such as hemicellulose, lignin and ash, were calculated as follows.

$$
\text { Recovery rate }(\%)=\frac{\text { Yield }}{\text { Component content of EWS }} \times 100 \%
$$

\section{Measurements}

Infrared (IR) spectroscopy was performed on an EQUINOX 55 spectrometer in the range of $500-4000 \mathrm{~cm}^{-1}$. Prior to analysis, the solid samples were grounded with dried $\mathrm{KBr}$ powder and compressed into a disk. X-ray diffraction (XRD) was performed on a X'Pert Pro diffractometer with $\mathrm{CuK \alpha}$ radiation at $40 \mathrm{kV}$ and $40 \mathrm{~mA}$ in the range from $10^{\circ}$ to $80^{\circ}$, and the scanning rate was $5^{\circ} / \mathrm{min}$. The surface morphologies of wheat straw and its derivatives were observed using a scanning electron microscopy (SEM) microscope (Hitachi N-3000 apparatus), and a thin layer of gold was sputtered onto the sample prior to imaging. Elemental analysis (EA) was performed on a Vario EL III elemental analyzer. Specific surface areas were calculated using the BET model on a NOVA 2000e fully automatic specific surface and porosity analyzer. X-ray photoelectron spectroscopy (XPS) was recorded on a Kratos XSAM800 spectrometer with MgKa radiation $(1253.6 \mathrm{eV})$, which was operated at $12 \mathrm{kV}$ and $10 \mathrm{~mA}$ without a monochromator. The qualitative analysis of sugars was performed on a LC-100 PLUS HPLC equipped with a Rezex ROA column (Phenomenex) and a refractive index detector (Shimadzu Corp., Kyoto, Japan) at $63{ }^{\circ} \mathrm{C}$ using $\mathrm{H}_{2} \mathrm{SO}_{4}(4 \mathrm{mM})$ as an eluent at a flow rate of $0.6 \mathrm{~mL} / \mathrm{min}$. HPLC-MS was performed on Waters Arc HPLC-2998 PDA-QDa equipped with YMC ODS-A $(5 \mu \mathrm{m}, 4.6 \times 250 \mathrm{~mm})$ using $85 \mathrm{wt} \%$ acetonitrile-water as the mobile phase at a flow rate of $1.0 \mathrm{~mL} / \mathrm{min}$. Nuclear magnetic resonance (NMR) including ${ }^{1} \mathrm{H}$ NMR and ${ }^{13} \mathrm{C}$ NMR spectra were acquired on a Unity-Inova 600 at $50{ }^{\circ} \mathrm{C}$ using DMSO-d6 as solvent and tetramethylsilane as internal standard. The molecular weight of lignin was determined using Waters E2695 GPC (see Additional file 1).

$$
\text { Componenet yield }(\%)=\frac{\text { Mass of component isolated from wheat straw }}{\text { Mass of EWS }} \times 100 \% \text {, }
$$

$$
\text { Removal rate }(\%)=\left(1-\frac{\text { Amount of component in isolated cellulose }}{\text { Total amount of component in EWS }}\right) \times 100 \% \text {, }
$$

$$
\text { Theoretical yield of lignin }(\%)=\frac{\text { Removal rate of lignin } \times \text { Lignin content in EWS } \times \text { Mass of EWS }}{\text { Mass of EWS }} \times 100 \% \text {, }
$$


The quantitative analysis of HMF derived from wheat straw cellulose was determined by a GC2020 gas chromatography equipped with a HP-1 capillary column (30 $\mathrm{m} \times 0.25 \mathrm{~mm} \times 0.25 \mu \mathrm{m})$. The initial temperature was retained at $50{ }^{\circ} \mathrm{C}$ for $3 \mathrm{~min}$, then ramped to $230{ }^{\circ} \mathrm{C}$ at $10{ }^{\circ} \mathrm{C} / \mathrm{min}$, and held at this final temperature for $5 \mathrm{~min}$. The gasification and detector temperatures were 240 and $260{ }^{\circ} \mathrm{C}$, respectively. Glucose derived from cellulose was determined by DNS method using a UV measurement at $540 \mathrm{~nm}$ [28]. The quantitative analysis of the reaction product derived from lignin was performed on a LC-100 PLUS HPLC equipped with reversed-phase NovapakC18-100 silica column $(4.6 \times 150 \mathrm{~mm}, 4 \mu \mathrm{m})$ and UV detector. The mixture of acetonitrile: $1 \mathrm{wt} \%$ phosphoric acid solution $(12: 88, \mathrm{v} / \mathrm{v})$ was employed as mobile phase at the flow rate of $1.2 \mathrm{~mL} / \mathrm{min}$ with column temperature at $32{ }^{\circ} \mathrm{C}$.

\section{Results and discussion Characterization \\ IR}

To separate cellulose from other components well, the reaction conditions were optimized by changing $\mathrm{H}_{2} \mathrm{SO}_{4}$ concentration, reaction temperature and time, thus obtaining cellulose under various conditions. The IR spectra of EWS and cellulose samples are presented in Fig. 1. In the IR spectrum of EWS (curve a), the small shoulder bands at 1734 and $1509 \mathrm{~cm}^{-1}$ correspond to the characteristic adsorption of aliphatic esters of hemicellulose and $\mathrm{C}=\mathrm{C}$ of bound lignin, respectively [26]. The band at $1160 \mathrm{~cm}^{-1}$ is assigned to the stretching vibration and $\mathrm{C}-\mathrm{O}-\mathrm{C}$ stretching vibration of $\beta-1,4$-glucosidic

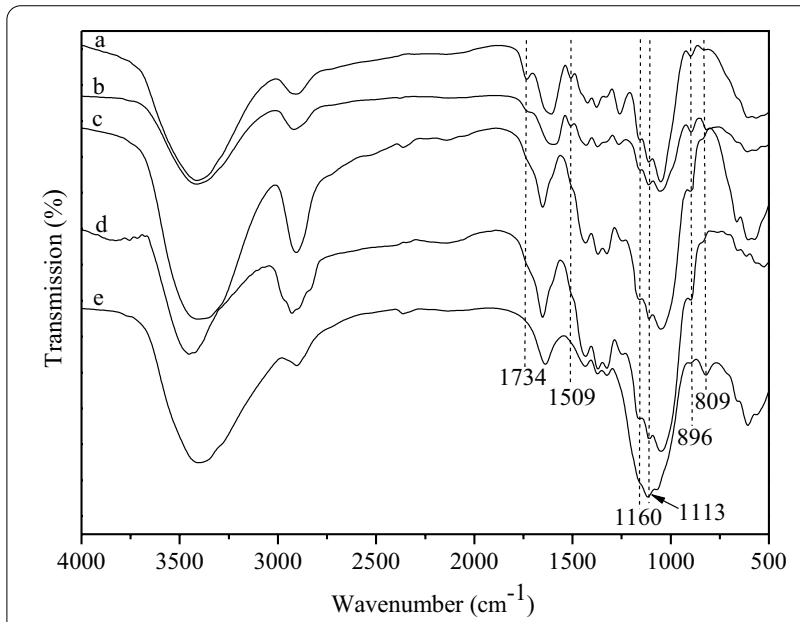

Fig. $1 \mathrm{IR}$ spectra of (a) EWS, (b) cellulose isolated at $150^{\circ} \mathrm{C}$ with 1.0 wt $\% \mathrm{H}_{2} \mathrm{SO}_{4^{\prime}}$ (c) cellulose isolated at $150^{\circ} \mathrm{C}$ with $1.5 \mathrm{wt} \% \mathrm{H}_{2} \mathrm{SO}_{4^{\prime}}$ (d) cellulose isolated at $180^{\circ} \mathrm{C}$ with $1.0 \mathrm{wt} \% \mathrm{H}_{2} \mathrm{SO}_{4}$ and (e) cellulose isolated at $180^{\circ} \mathrm{C}$ with $1.5 \mathrm{wt} \% \mathrm{H}_{2} \mathrm{SO}_{4}$ bonds. Moreover, the band at $896 \mathrm{~cm}^{-1}$ is attributed to the $\mathrm{C}-\mathrm{H}$ bending vibration of $\beta-1,4$-glucosidic bonds, which is the characteristic band of cellulose in the fingerprint region [29]. The band at $1113 \mathrm{~cm}^{-1}$ belongs to the asymmetrical stretching vibration of $\mathrm{Si}-\mathrm{O}-\mathrm{Si}$ and/ or the stretching vibration of both $\mathrm{C}-\mathrm{O}$ and $\mathrm{C}-\mathrm{O}-\mathrm{C}$ bonds [30,31] In the spectrum of cellulose isolated at $150{ }^{\circ} \mathrm{C}$ with 1.0 wt $\% \mathrm{H}_{2} \mathrm{SO}_{4}$ (curve b), the characteristic bands around 1734 and $1509 \mathrm{~cm}^{-1}$ belonged to hemicellulose and lignin become weaker, indicating that most hemicellulose and lignin have been removed from EWS. Similarly, in the spectrum of cellulose isolated at $150{ }^{\circ} \mathrm{C}$ with $1.5 \mathrm{wt} \% \mathrm{H}_{2} \mathrm{SO}_{4}$ (curve c), the characteristic bands of hemicellulose and lignin almost disappear. However, compared with curve b, the characteristic bands around 1160 and $896 \mathrm{~cm}^{-1}$ become weaker, indicating that cellulose content decreases at higher $\mathrm{H}_{2} \mathrm{SO}_{4}$ concentration. Moreover, the stretching vibrations of $\mathrm{Si}-\mathrm{O}-\mathrm{Si}, \mathrm{C}-\mathrm{O}$ and $\mathrm{C}-\mathrm{O}-\mathrm{C}$ bonds around $1113 \mathrm{~cm}^{-1}$ become stronger. Figure 1 also indicates that characteristic adsorptions in the IR spectrum (curve d) of cellulose obtained at $180{ }^{\circ} \mathrm{C}$ with $1.0 \mathrm{wt} \% \mathrm{H}_{2} \mathrm{SO}_{4}$ is similar to those in curve c. Although cellulose isolated at $180{ }^{\circ} \mathrm{C}$ with $1.5 \mathrm{wt} \% \mathrm{H}_{2} \mathrm{SO}_{4}$ possesses similar characteristic adsorption (curve e) to that observed in curves $\mathrm{c}$ and $\mathrm{d}$, the characteristic band around $809 \mathrm{~cm}^{-1}$ clearly appears, confirming the formation of humins at higher temperature and acid concentration. Generally, humims is the byproduct derived from the intermolecular polymerization of lignocellulose [32]. Additionally, the characteristic bands around 1160 and $896 \mathrm{~cm}^{-1}$ almost disappear in curves e, revealing cellulose content decreases considerably.

Factually, lignin could be directly precipitated from the residual liquid obtained at the first stage. After

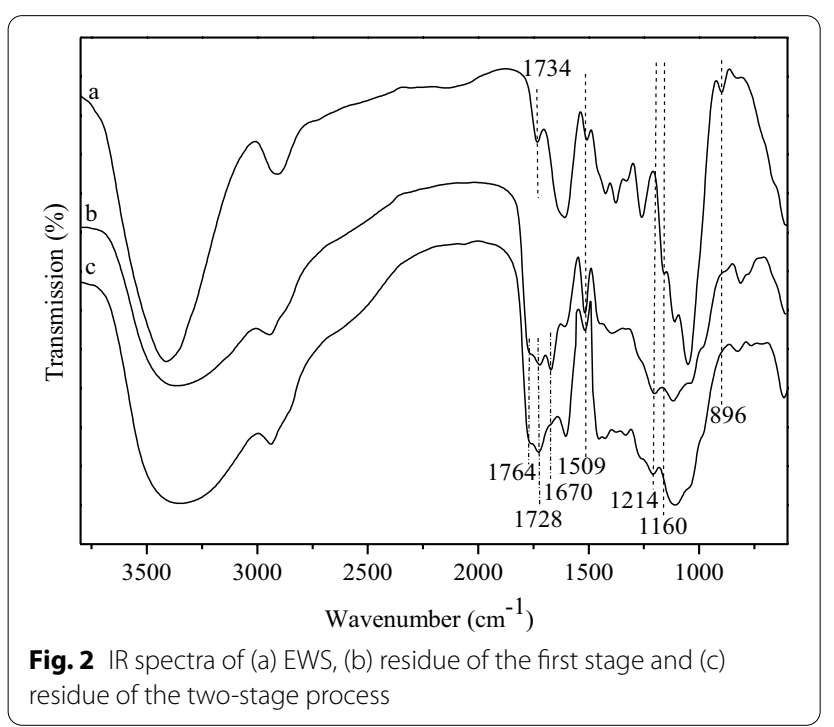


precipitating lignin, both residual liquids obtained at the first stage and the two-stage process were concentrated, thus giving residues. The IR spectra of the residues are shown in Fig. 2. Compared with the IR spectrum of EWS (curve a), the characteristic absorption bands at 1160 and $896 \mathrm{~cm}^{-1}$ attributed to cellulose hardly appear while the characteristic bands of hemicellulose and lignin still exist at 1728 and $1509 \mathrm{~cm}^{-1}$ (curves b and c). These results indicate that cellulose is almost completely separated from hemicellulose and lignin. The existence of the characteristic band at $1728 \mathrm{~cm}^{-1}$ indicates that the hydrolysis of hemicellulose is incomplete, which is possible ascribed to lower catalyst concentration. However, the characteristic band belonged to hemicellulose shifts to a lower wavenumber and the red shift occurs. It can be explained by the instability of hemicellulose structure resulted from chemical changes during the separation process. Moreover, new absorption bands at 1764, 1670 and $1214 \mathrm{~cm}^{-1}$ are observed in the residue obtained by the first stage process (curve b). However, characteristic absorption band at $1670 \mathrm{~cm}^{-1}$ almost disappears in the IR spectrum of the residue obtained by the two-stage process (curve c). Therefore, we speculate that the band possibly belongs to oligomers derived from hemicellulose, which further hydrolyzes and thus is not detected at higher temperature and catalyst concentration. The comparison between curves $b$ and $c$ indicates that the characteristic absorption band of lignin at $1509 \mathrm{~cm}^{-1}$ becomes weaker in curve c. It reveals that the two-stage process is beneficial for promoting the extraction of lignin.

Figure 1 displays that higher temperature and catalyst concentration have a negative effect on cellulose purity. Therefore, it could be reasonable to conclude that the favorable conditions for the separation of cellulose from hemicellulose and lignin are lower temperature and $\mathrm{H}_{2} \mathrm{SO}_{4}$ concentration while the complete separation of hemicellulose and lignin on the contrary. A two-step process must be helpful for the isolation of cellulose and lignin from wheat straw. In this work, the first-stage and the second-stage were carried out at $150{ }^{\circ} \mathrm{C}$ with $1.0 \mathrm{wt} \%$ $\mathrm{H}_{2} \mathrm{SO}_{4}$ and $180{ }^{\circ} \mathrm{C}$ with 1.5 wt $\% \mathrm{H}_{2} \mathrm{SO}_{4}$, respectively. Therefore, cellulose samples obtained under these two conditions will be further characterized by XRD, SEM, EA and BET.

\section{$X R D$}

Figure 3 shows the XRD patterns of EWS and cellulose isolated from wheat straw. The peak at $22.4^{\circ}$ of (002) reflection is attributed to the typical crystal lattice of cellulose $\mathrm{I}_{\beta}$, which presents in every plot. It indicates that all samples exhibit the diffuse characteristic pattern of an amorphous phase [33]. A shoulder peak at $16.1^{\circ}$ of (101) reflection and a weak peak at $34.2^{\circ}$ of (040) reflection

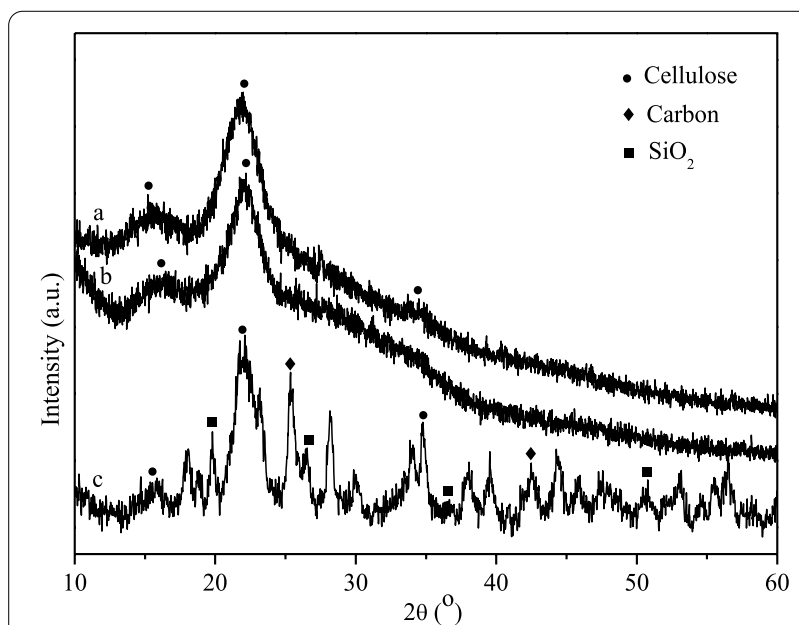

Fig. 3 XRD patterns of (a) EWS, (b) cellulose isolated at $150{ }^{\circ} \mathrm{C}$ with $1.0 \mathrm{wt} \% \mathrm{H}_{2} \mathrm{SO}_{4}$ and (c) cellulose isolated at $180^{\circ} \mathrm{C}$ with $1.5 \mathrm{wt} \% \mathrm{H}_{2} \mathrm{SO}_{4}$

appears in the EWS pattern (curve a), which are attributed to cellulose phase. Compared to the pattern of EWS, there is no obvious change in the pattern of cellulose obtained at lower temperature and acid concentration (curve b). However, new diffraction peaks are observed in curve c, revealing that the phase structure of cellulose isolated at higher temperature and acid concentration becomes more complex. Broad diffraction peaks related to carbon appeared at $25.3^{\circ}$ and $42.5^{\circ}$ are also observed [34]. The former and the latter are assigned to the plane $\mathrm{C}$ (002) reflection [35] and (100/101) reflection of graphitic and/or organized carbon [36], respectively. These results indicate that cellulose is doped with charcoal, possibly derived from humins, leading to the formation of carbon fibers at higher temperatures and catalyst concentration [37]. Moreover, amorphous phase, with minor peaks at $19.8^{\circ}, 26.5^{\circ}, 36.4^{\circ}$ and $50.5^{\circ}$ attributed to the presence of mineral $\mathrm{SiO}_{2}$, is observed in curve c [38]. These results are consistent with the IR spectrum of cellulose isolated at higher temperature and acid concentration, as shown in Fig. 1c-e. Both the IR and XRD results show that the removal of ash, mainly composed of $\mathrm{SiO}_{2}$, becomes difficult at a higher catalyst amount and temperature. It could be ascribed to the formation of carbon fibers, leading to ash adsorption on the surface of sample due to its excellent adsorption properties [39, 40].

\section{SEM}

The morphologies of EWS, cellulose isolated from wheat straw under various conditions are observed using SEM. The SEM images in Fig. 4 show that all samples display irregular and featureless image with a thick sheet-like structure. There is almost no difference in the image of EWS and cellulose obtained at lower temperature and 
a

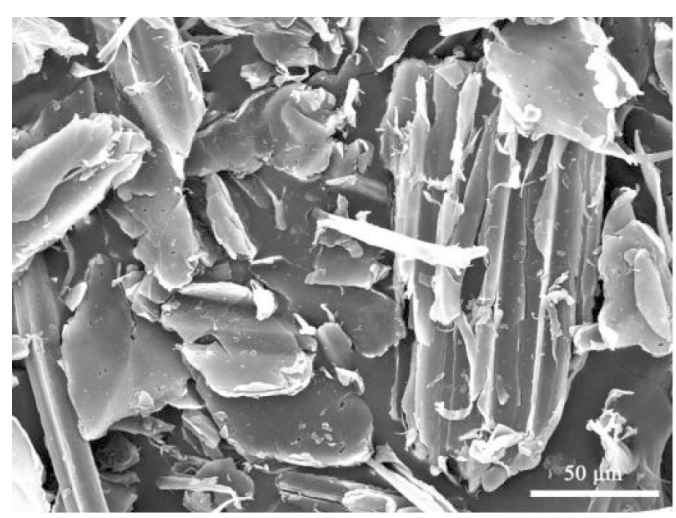

c b

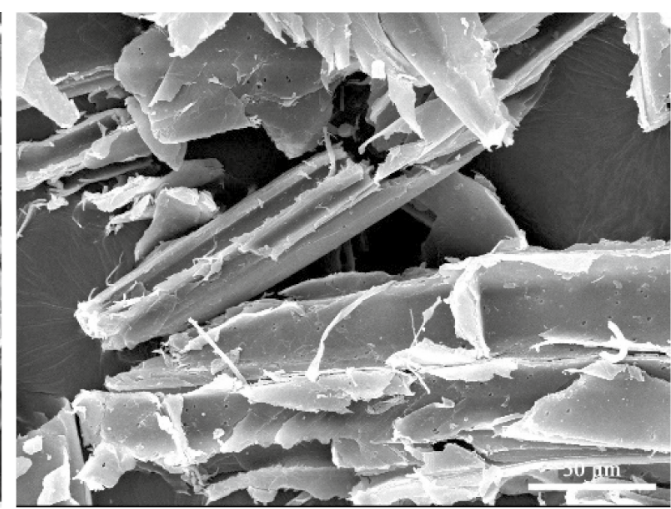

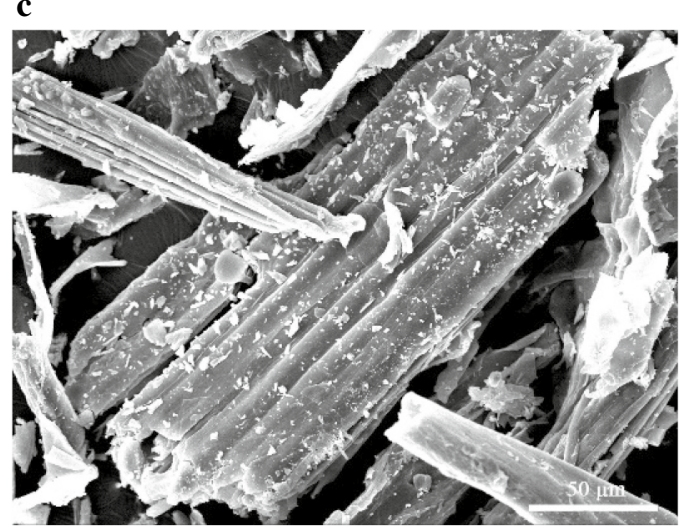

Fig. 4 SEM of (a) EWS, (b) cellulose isolated at $150{ }^{\circ} \mathrm{C}$ with $1.0 \mathrm{wt} \% \mathrm{H}_{2} \mathrm{SO}_{4}$ and (c) cellulose isolated at $180{ }^{\circ} \mathrm{C}$ with $1.5 \mathrm{wt} \% \mathrm{H}_{2} \mathrm{SO}_{4}$

Table $1 \mathrm{EA}$ and BET results of cellulose isolated from wheat straw

\begin{tabular}{|c|c|c|c|c|}
\hline \multirow[t]{2}{*}{ Treated conditions } & \multicolumn{3}{|c|}{ Content (wt\%) } & \multirow{2}{*}{$\begin{array}{l}\text { BET surface } \\
\text { area }\left(\mathrm{m}^{2} / \mathrm{g}\right)\end{array}$} \\
\hline & C & $\mathbf{H}$ & $\mathbf{N}$ & \\
\hline $150^{\circ} \mathrm{C}, 6 \mathrm{~h}, 1.0 \mathrm{wt} \% \mathrm{H}_{2} \mathrm{SO}_{4}$ & 25.592 & 5.046 & 0.061 & 13.7 \\
\hline $180^{\circ} \mathrm{C}, 2.5 \mathrm{~h}, 1.5 \mathrm{wt} \% \mathrm{H}_{2} \mathrm{SO}_{4}$ & 34.990 & 5.338 & 0.063 & 31.8 \\
\hline
\end{tabular}

acid concentration (Fig. 4b). However, a large number of surface attachments are observed in the image of cellulose samples obtained at higher temperature and acid concentration (Fig. 4c). It also could be ascribed to the promotion in ash adsorption because of the formation of carbon fibers [40], as shown in the IR spectrum (Fig. 1d) and XRD pattern (Fig. 3c).

\section{EA and BET}

Table 1 shows the EA and BET results of cellulose isolated from wheat straw under various conditions. The contents of $\mathrm{H}$ and $\mathrm{N}$ elements are close while obvious difference in the content of $\mathrm{C}$ element is observed by varying temperature and acid concentration. Note that $\mathrm{C}$ content increases by elevating catalyst concentration and temperature. 25.592 and $34.990 \mathrm{wt} \% \mathrm{C}$ contents are obtained at $150{ }^{\circ} \mathrm{C}$ for $6 \mathrm{~h}$ with $1.0 \mathrm{wt} \% \mathrm{H}_{2} \mathrm{SO}_{4}$ and at $180{ }^{\circ} \mathrm{C}$ for $2.5 \mathrm{~h}$ with $1.5 \mathrm{wt} \% \mathrm{H}_{2} \mathrm{SO}_{4}$, respectively. It could be ascribed to the formation of charcoal at higher $\mathrm{H}_{2} \mathrm{SO}_{4}$ concentration and temperature [37], which agrees with the XRD pattern shown in Fig. 3.

The surface areas of both cellulose samples are low, giving 13.7 and $31.8 \mathrm{~m}^{2} / \mathrm{g}$, respectively. However, compared to cellulose obtained at lower temperature and $\mathrm{H}_{2} \mathrm{SO}_{4}$ concentration, the surface area of the sample obtained at higher temperature and $\mathrm{H}_{2} \mathrm{SO}_{4}$ concentration increases. The increase in the surface area may be attributed to the formation of charcoal and carbon fibers [40], which possibly leads to the introduction of $\mathrm{Si}$ into samples. Consequently, the characteristic absorption band and diffraction peak of $\mathrm{SiO}_{2}$ become stronger in Figs. 1e and 3c.

\section{Isolation of cellulose and lignin from wheat straw Isolation of cellulose and lignin via one-stage process} Cellulose and lignin were generally isolated by a onestage organoslov process, in which ethanol, methanol 
Table 2 Cellulose and lignin isolated from wheat straw via one-stage process

\begin{tabular}{llllll}
\hline Entry & Organic solvent & $\begin{array}{l}\text { Cellulose } \\
\text { yield (\%) }\end{array}$ & $\begin{array}{l}\text { Lignin } \\
\text { yield } \\
\text { (\%) }\end{array}$ & $\begin{array}{l}\text { Cellulose } \\
\text { purity } \\
\text { (wt\%) }\end{array}$ & $\begin{array}{l}\text { Lignin } \\
\text { purity } \\
\text { (wt\%) }\end{array}$ \\
\hline 1 & Ethanol & 63.5 & 2.7 & 76.4 & 90.3 \\
2 & Methanol & 60.7 & 2.3 & 78.8 & 91.2 \\
3 & 1,4-dioxane & 59.7 & 3.5 & 79.1 & 89.7 \\
\hline
\end{tabular}

Reaction conditions: $15 \mathrm{~g} \mathrm{EWS}, 150^{\circ} \mathrm{C}$ for $6 \mathrm{~h}$ with $0.5 \mathrm{wt} \% \mathrm{H}_{2} \mathrm{SO}_{4}$

and 1,4-dioxane are often employed as organic solvent [20]. Therefore, the isolation of cellulose and lignin was first carried out in these solvents. The results in Table 2 showed that ethanol, methanol and 1,4-dioxane displayed similar performance in terms of cellulose and lignin yields, varying in the range from 59.7 to $63.5 \%$ and 2.7 to $3.5 \mathrm{wt} \%$, respectively. The similar results possibly could be ascribed to the dissolution of lignin mainly depends on the hydrogen bonding ability while not the polarity of solvent. The purity of cellulose and lignin varied in the small range from 76.4 to $79.1 \mathrm{wt} \%$ and 89.7 to $91.2 \mathrm{wt} \%$. Although the yield and purity of cellulose, the purity of lignin were acceptable, lignin yield was almost ignored. The isolation of cellulose and lignin from wheat straw requires further optimization.

The compositions of cellulose obtained in various organic solvent were determined, and compared with those of wheat straw as well as EWS. The results in Table 3 indicated that wheat straw is composed of 52.4, 18.2, 18.8 and $3.7 \mathrm{wt} \%$ cellulose, hemicellulose, lignin and ash. All component contents increased after extracting in the mixture of toluene and ethanol. The contents of cellulose, hemicellulose, lignin and ash were 56.0, 19.5, 20.1 and $4.0 \mathrm{wt} \%$ in EWS. It could be attributed to the effective removal of soluble impurities such as grease and wax. Cellulose contents in cellulose samples obtained in

Table 3 Composition of wheat straw and isolated cellulose

\begin{tabular}{lllll}
\hline Sample & \multicolumn{4}{l}{ Component content $(\boldsymbol{w t} \%)$} \\
\cline { 2 - 5 } & Cellulose & Hemicellulose & Lignin & Ash \\
\hline Wheat straw & 52.4 & 18.2 & 18.8 & 3.7 \\
EWS & 56.0 & 19.5 & 20.1 & 4.0 \\
Cellulose $^{\mathrm{a}, \mathrm{b}}$ & 78.8 & 3.9 & 12.1 & 3.1 \\
Cellulose $^{\mathrm{a}, \mathrm{c}}$ & 76.4 & 3.5 & 12.7 & 2.8 \\
Cellulose $^{\mathrm{a}, \mathrm{d}}$ & 79.1 & 4.3 & 11.7 & 2.9
\end{tabular}

a Reaction conditions: $150{ }^{\circ} \mathrm{C}$ for $6 \mathrm{~h}$ with $0.5 \mathrm{wt} \% \mathrm{H}_{2} \mathrm{SO}_{4}$ in organic $/ \mathrm{H}_{2} \mathrm{O}$ mixture $(1: 2, \mathrm{v} / \mathrm{v})$

b Ethanol $/ \mathrm{H}_{2} \mathrm{O}$ as solvent

c Methanol/ $\mathrm{H}_{2} \mathrm{O}$ as solvent

d 1,4-dioxane $/ \mathrm{H}_{2} \mathrm{O}$ as solvent various solvents were close, varying in the range from 76.4 to $79.1 \mathrm{wt} \%$. Compared to wheat straw and EWS, cellulose content increased sharply, it must be due to the removal of hemicellulose and lignin.

The removal rates of hemicellulose and lignin were then calculated based on the composition of EWS and the isolated cellulose samples, the formula for calculating removal rate given in the "Determination and calculation" section, as shown in Fig. 5. The removal rates of hemicellulose almost reached up $90 \%$ and the removal rate of lignin slightly varied in the range from 59.8 to $65.2 \%$. Therefore, it is reasonable to conclude that most hemicellulose and lignin were effectively separated from cellulose via one-stage process. However, lignin yields listed in Table 2 were almost ignored. According to the formula for calculating the theoretical yield of lignin given in the "Determination and calculation" section, lignin content in EWS and the removal rate shown in Table 3 and Fig. 5, the theoretical yield of lignin should be in a range from 12.0 to $13.1 \%$, which is much higher than actual lignin yields presented in Table 2. It is well-known that hemicellulose links with cellulose and lignin via hydrogen bonds and phenolic acid in lignocellulose, respectively [41]. The hydrogen bond between hemicellulose and cellulose must be easy to break because of its nature in physical connection, thus yielding a high removal rate of hemicellulose, as shown in Fig. 5. However, oligomers are possibly produced because of incomplete hydrolysis of hemicellulose, as shown in Fig. 2. Consequently, the connection between hemicellulose and lignin may not be effectively destroyed since hemicellulose and lignin are connected with ferulic acid via chemical ester bond and ether bond, leading to the formation of stable bridging

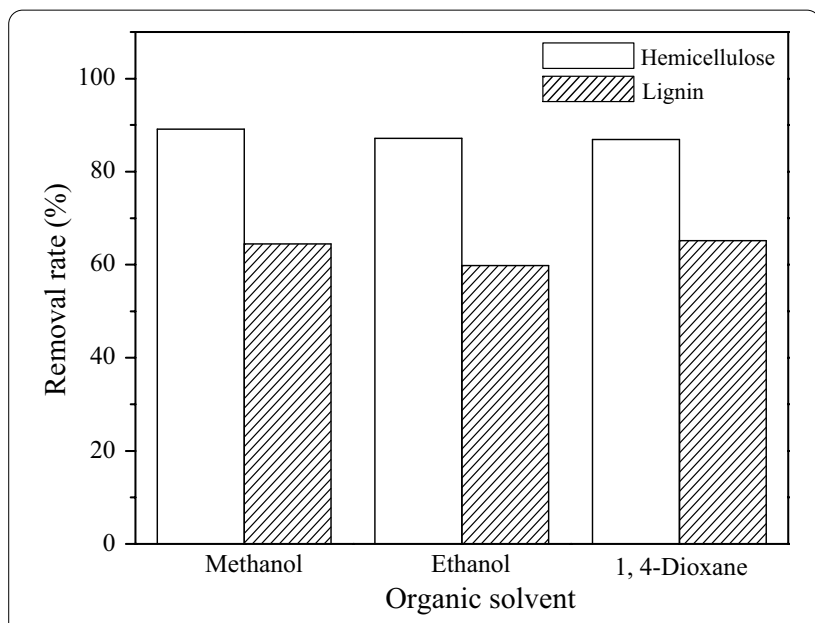

Fig. 5 Removal rate of hemicellulose and lignin as function of organic solvent via the one-stage process. Reaction conditions: $150{ }^{\circ} \mathrm{C}$ for $6 \mathrm{~h}$ with $0.5 \mathrm{wt} \% \mathrm{H}_{2} \mathrm{SO}_{4}$ in organic/ $\mathrm{H}_{2} \mathrm{O}$ mixture $(1: 2, \mathrm{v} / \mathrm{v})$ 
structure of lignin-ether-ferulic acid-ester-hemicellulose (Lignin-Carbohydrate Complex, LCC). Therefore, it is difficult to precipitate lignin due to large amounts of hydrophilic groups of hemicellulose, giving poor yield of lignin.

The isolation of cellulose and lignin was further investigated by the one-stage process using 1,4-dioxane as solvent in detail since it displayed slightly better performance than ethanol and methanol in terms of cellulose purity and lignin yield. The amount of organic solvent, catalyst concentration and temperature are key parameters for organosolv fractionation [42]. Therefore, the reaction conditions were optimized by changing the type and amount of organic solvent, $\mathrm{H}_{2} \mathrm{SO}_{4}$ concentration, reaction temperature and time, and the results were shown in Table 4.

The amount of organic solvent was first adjusted (entries 1-4). The results in Table 4 displayed that the yield of cellulose gradually dropped while the purity of cellulose increased with increasing the amount of organic solvent (entries 1-3). Then, the purity of cellulose slightly decreased once the volume ratio of 1,4-dioxane to $\mathrm{H}_{2} \mathrm{O}$ reached 3:1 (entry 4). Note that the yield of lignin was always enhanced with increasing the amount of organic solvent. The yield of lignin reached $9.4 \%$ with a 3:1 volume ratio of 1,4-dioxane to $\mathrm{H}_{2} \mathrm{O}$ (entry 4). This behavior could be attributed to enhancement in the dissolution of lignin with increasing the amount of organic solvent. Table 4 shows that the amount of organic solvent displayed an insignificant effect on the purity of lignin, which changed in a small range from 88.4 to $91.0 \mathrm{wt} \%$ (entries 1-4).

The concentration of $\mathrm{H}_{2} \mathrm{SO}_{4}$ was varied in the range from 0.5 to $2.0 \mathrm{wt} \%$ (entries $3,5-7$ ). Large impact on the yield and purity of cellulose was observed. The yield of cellulose decreased while the purity changed contrarily when $\mathrm{H}_{2} \mathrm{SO}_{4}$ concentration was enhanced from 0.5 to 1.0 wt $\%$. The minimum yield of $55.2 \%$ and maximum purity of $86.8 \mathrm{wt} \%$ were achieved with $1.0 \mathrm{wt} \% \mathrm{H}_{2} \mathrm{SO}_{4}$ (entry 5). It could be ascribed to the improvement in the removal of both hemicellulose and lignin at higher $\mathrm{H}_{2} \mathrm{SO}_{4}$ concentration. The recovery rate of cellulose reached up $92.8 \%$ according to the results in Table 4 and formula for calculating recovery rate given in the "Determination and calculation" section. However, additional increase in $\mathrm{H}_{2} \mathrm{SO}_{4}$ concentration had a negative effect (entries 6, 7). The purity of cellulose reduced to $69.5 \mathrm{wt} \%$ when $\mathrm{H}_{2} \mathrm{SO}_{4}$ concentration reached $2.0 \mathrm{wt} \%$ (entry 7). This could be attributed to the enhancement in the formation of biochar at higher acid concentration, as shown in Fig. 3c. The as-formed biochar produces carbon fibers with cellulose, leading to increase in the yield but decrease in the purity. Table 4 showed that lignin yield also increased with increase in $\mathrm{H}_{2} \mathrm{SO}_{4}$ concentration (entries 3, 5, 6). The yield of lignin increased from 8.7 to $11.2 \%$ as $\mathrm{H}_{2} \mathrm{SO}_{4}$ concentration was enhanced from 0.5 to $1.5 \mathrm{wt} \%$. It is possibly attributed to the improvement in the hydrolysis of hemicellulose at higher acid concentration, which reduces the formation of oligomer derived from hemicellulose. Therefore, the connection between hemicellulose and lignin was destroyed more effectively, and promoted the separation of lignin. The yield of lignin then almost remained constant with further increase in $\mathrm{H}_{2} \mathrm{SO}_{4}$ concentration (entries 6, 7). However, it can be seen from Table 4 that $\mathrm{H}_{2} \mathrm{SO}_{4}$ concentration displayed little effect on the purity of lignin, which varied in a small range from 90.3 to $91.2 \mathrm{wt} \%$ (entries 3, 5-7). It is speculated that once lignin is separated from other components, it is easy to precipitate alone. Therefore, lignin yield changed while purity did not by varying $\mathrm{H}_{2} \mathrm{SO}_{4}$ concentration. It

Table 4 Optimization for cellulose and lignin isolated from wheat straw via a one-stage process

\begin{tabular}{|c|c|c|c|c|c|c|c|c|}
\hline Entry & $\begin{array}{l}\text { Organic solvent/ } \\
\mathrm{H}_{2} \mathrm{O}(\mathrm{v} / \mathrm{v})\end{array}$ & $\begin{array}{l}\mathrm{H}_{2} \mathrm{SO}_{4} \\
\text { concentration } \\
\text { (wt\%) }\end{array}$ & $t(h)$ & $\mathrm{T}\left({ }^{\circ} \mathrm{C}\right)$ & $\begin{array}{l}\text { Cellulose } \\
\text { yield (\%) }\end{array}$ & $\begin{array}{l}\text { Cellulose purity } \\
\text { (wt\%) }\end{array}$ & Lignin yield (\%) & $\begin{array}{l}\text { Lignin } \\
\text { purity } \\
\text { (wt\%) }\end{array}$ \\
\hline 1 & $1: 2$ & 0.5 & 6 & 150 & 59.7 & 79.1 & 3.5 & 89.7 \\
\hline 2 & $1: 1$ & 0.5 & 6 & 150 & 57.4 & 78.6 & 6.5 & 89.5 \\
\hline 3 & $2: 1$ & 0.5 & 6 & 150 & 56.3 & 81.6 & 8.7 & 91.0 \\
\hline 4 & $3: 1$ & 0.5 & 6 & 150 & 57.2 & 75.4 & 9.4 & 88.4 \\
\hline 5 & $2: 1$ & 1.0 & 6 & 150 & 55.2 & 86.8 & 9.9 & 90.3 \\
\hline 6 & $2: 1$ & 1.5 & 6 & 150 & 62.1 & 75.6 & 11.2 & 91.2 \\
\hline 7 & $2: 1$ & 2.0 & 6 & 150 & 65.3 & 69.5 & 11.4 & 90.6 \\
\hline 8 & $2: 1$ & 1.5 & 6 & 180 & 68.7 & 64.9 & 14.6 & 90.3 \\
\hline 9 & $2: 1$ & 1.5 & 2.5 & 180 & 64.3 & 66.7 & 13.5 & 90.8 \\
\hline 10 & $2: 1$ & 1.0 & 2.5 & 180 & 54.0 & 76.4 & 12.2 & 87.9 \\
\hline
\end{tabular}

Reaction conditions: $15 \mathrm{~g}$ EWS, $\mathrm{H}_{2} \mathrm{SO}_{4}$ as catalyst, 1,4-dioxane/ $\mathrm{H}_{2} \mathrm{O}$ mixture as solvent 
can be seen from Table 4 that lignin yield was improved by increasing the amount of organic solvent or acid concentration (entries 1-7), and the maximum lignin yield of $11.4 \%$ was observed (entry 7). However, it was considerably lower than that of $20.1 \mathrm{wt} \%$ lignin content in EWS. Therefore, EWS was further treated at higher temperature of $180{ }^{\circ} \mathrm{C}$ (entry 8) according to the previously reported procedure [43]. As expected, higher lignin yield of $14.6 \%$ was acquired. However, the purity of cellulose decreased, only $64.9 \mathrm{wt} \%$ was observed. It is no doubt that the hydrolysis of hemicellulose and the formation of biochar also became easy to occur at higher temperature.

Moreover, the reaction time was varied. Reduction in the reaction time led to drop in the yields of cellulose and lignin but slight increase in the purity of cellulose (entries 8,9 ), indicating that reaction time may be an important parameter with respect to a side reaction. The reaction time had an obvious effect on lignin yield, which decreased from 14.6 to $13.5 \%$ as the reaction time was reduced from 6 to $2.5 \mathrm{~h}$. However, even with less time, higher lignin yield was observed at $180{ }^{\circ} \mathrm{C}$ than that obtained at $150{ }^{\circ} \mathrm{C}$ (entries $5,6,9,10$ ). This could be ascribed to both the hydrolysis of hemicellulose and the dissolution of lignin were promoted at higher temperature. As a result, the breakage of chemical linkage between hemicellulose and lignin increased, and the separation became more complete.

In order to understand the effect of temperature and catalyst amount on the extraction process well, cellulose isolated from wheat straw was calcined and the color of the calcined residue was observed. Obvious difference in the color of the calcined residue was observed under various conditions. Instead of pure white residue, which was mainly composed of $\mathrm{SiO}_{2}$, gray white residue was obtained at higher temperature and catalyst amount (Table 4, entries 6-10). It revealed that other chemical process, which may be resulted from the side reaction, besides the hydrolysis of hemicellulose occurred. Moreover, EWS was replaced by commercial cellulose or xylose (the primary component of hemicellulose), which was also treated in 1,4-dioxane $/ \mathrm{H}_{2} \mathrm{O}$ mixture $(2: 1, \mathrm{v} / \mathrm{v})$ at $180{ }^{\circ} \mathrm{C}$ for $2.5 \mathrm{~h}$ with $1.5 \mathrm{wt} \% \mathrm{H}_{2} \mathrm{SO}_{4}$. After pretreatment, the solid samples were collected and calcined, giving white and black residues, respectively. It further confirmed that the carbonization was mainly derived from hemicellulose during the organosolv process, which is consistent with the results given in Figs. 3, 4 and Table 1.

Experiments 5 and 9 in Table 4 indicated that excellent separation was obtained in terms of cellulose purity (86.8 wt\%) or lignin yield (13.5\%). However, only single component was effectively obtained. Cellulose samples obtained in these experiments were further analyzed to determine the removal rates of hemicellulose and lignin. The results in Table 5 revealed that both the removal rates of hemicellulose and lignin were close in experiments 5 and 9. Removal rates of 91.8 and $81.6 \%$ were obtained at $150{ }^{\circ} \mathrm{C}$ for $6 \mathrm{~h}$ with $0.5 \mathrm{wt} \% \mathrm{H}_{2} \mathrm{SO}_{4}$, and those of 96.2 and $82.2 \%$ at $180{ }^{\circ} \mathrm{C}$ for $2.5 \mathrm{~h}$ with $1.5 \mathrm{wt} \% \mathrm{H}_{2} \mathrm{SO}_{4}$. These results showed that hemicellulose and lignin could be effectively separated from cellulose even at lower temperature and acid concentration. However, lignin yield of $9.9 \%$ obtained at $150{ }^{\circ} \mathrm{C}$ with $0.5 \mathrm{wt} \% \mathrm{H}_{2} \mathrm{SO}_{4}$ was much lower than that of $13.5 \%$ obtained at $180{ }^{\circ} \mathrm{C}$ with 1.5 wt $\% \mathrm{H}_{2} \mathrm{SO}_{4}$, indicating that the separation of hemicellulose and lignin requires higher temperature and/or acid concentration because of the chemical connection [41]. Unfortunately, higher temperature and/or acid concentration had a negative impact on cellulose purity (Table 4, entry 9). The ash content significantly increased and only $24.9 \%$ removal rate of ash was observed at higher catalyst concentration and temperature (Table 5 , entry 2). It means that considerable amount of ash remained with cellulose in the solid. The surface composition of cellulose obtained at $180{ }^{\circ} \mathrm{C}$ with $1.5 \mathrm{wt} \% \mathrm{H}_{2} \mathrm{SO}_{4}$ was analyzed by XPS. The surface Si content of $0.51 \mathrm{wt} \%$ was detected, which was much lower than the ash content in cellulose at $4.5 \mathrm{wt} \%$ detected according the reported procedure [27]. This could be attributed to the formation of carbon fibers, which promoted ash absorption within cellulose sample and thus led to decrease in the purity of cellulose, as shown in Figs. 1 and 3.

Table 5 Component content in cellulose and removal rate via one-stage process

\begin{tabular}{|c|c|c|c|c|c|c|c|c|}
\hline \multirow[t]{2}{*}{ Entry } & \multirow{2}{*}{$\begin{array}{l}\text { Concentration } \\
\text { (wt\%) }\end{array}$} & \multicolumn{4}{|l|}{$\begin{array}{l}\text { Component content } \\
\text { in cellulose (wt\%) }\end{array}$} & \multicolumn{3}{|c|}{ Removal rate (\%) } \\
\hline & & Cellulose & Hemicellulose & Lignin & Ash & Hemicellulose & Lignin & Ash \\
\hline $1^{\text {a }}$ & 0.5 & 86.8 & 2.9 & 6.5 & 1.4 & 91.8 & 81.6 & 80.7 \\
\hline $2^{b}$ & 1.5 & 66.7 & 1.1 & 5.2 & 4.5 & 96.2 & 82.2 & 24.9 \\
\hline
\end{tabular}

Reaction conditions: $15 \mathrm{~g}$ EWS, $\mathrm{H}_{2} \mathrm{SO}_{4}$ as catalyst, 1,4-dioxane/ $\mathrm{H}_{2} \mathrm{O}$ mixture as solvent $(2: 1, \mathrm{v} / \mathrm{v})$

a $150^{\circ} \mathrm{C}$ for $6 \mathrm{~h}$

b $180^{\circ} \mathrm{C}$ for $2.5 \mathrm{~h}$ 
Isolation of cellulose and lignin via two-stage process The results in Tables 2, 3 and 4 indicated that cellulose purity was acceptable but lignin yield was not at lower temperature and catalyst concentration. However, increase in temperature and catalyst concentration displayed an opposite tendency. Therefore, a two-stage process, which combined the conditions of experiments 5 and 9, was proposed to isolate cellulose and lignin from wheat straw. That is, the first stage was performed at $150{ }^{\circ} \mathrm{C}$ for $6 \mathrm{~h}$ in a mixture of 1,4-dioxane and $\mathrm{H}_{2} \mathrm{O}$ $(2: 1, \mathrm{v} / \mathrm{v})$ and the second stage was performed at $180{ }^{\circ} \mathrm{C}$ for $2.5 \mathrm{~h}$ with $1.5 \mathrm{wt} \% \mathrm{H}_{2} \mathrm{SO}_{4}$ concentration, as shown in Table 6. Surprisingly, lignin yield was significant enhanced and reached $17.4 \%$ (entry 1 ). These results further demonstrated that the cleavage of linkage between hemicellulose and lignin was possibly incomplete at the first stage. It was further enhanced at the second stage.

The reaction conditions, including $\mathrm{H}_{2} \mathrm{SO}_{4}$ concentration, reaction temperature and time for the second stage were further optimized. The acid concentration displayed similar influence on lignin yield to that observed in the one-stage process (entries 1-4). The yield of lignin was enhanced with increase in acid concentration, which could be ascribed to enhancement in the

Table 6 Optimization of parameters for the second stage

\begin{tabular}{llllll}
\hline Entry & $\begin{array}{l}\mathbf{H}_{\mathbf{2}} \mathbf{S O}_{\mathbf{4}} \\
\text { concentration } \\
(\mathbf{w t} \%)^{\mathbf{a}}\end{array}$ & $\mathbf{T}\left({ }^{\circ} \mathbf{C}\right)$ & $\mathbf{t}(\mathbf{h})$ & Lignin yield (\%)) & $\begin{array}{l}\text { Lignin } \\
\text { purity } \\
\text { (wt\%) }\end{array}$ \\
\hline 1 & 1.5 & 180 & 2.5 & 17.4 & 93.2 \\
2 & 1.0 & 180 & 2.5 & 14.1 & 89.5 \\
3 & 1.25 & 180 & 2.5 & 15.7 & 88.7 \\
4 & 1.75 & 180 & 2.5 & 14.7 & 86.8 \\
5 & 1.5 & 160 & 2.5 & 13.0 & 90.3 \\
6 & 1.5 & 170 & 2.5 & 15.7 & 90.8 \\
7 & 1.5 & 190 & 2.5 & 13.7 & 86.7 \\
8 & 1.5 & 180 & 1 & 16.4 & 93.1 \\
9 & 1.5 & 180 & 1.5 & 17.2 & 92.8 \\
10 & 1.5 & 180 & 6 & 17.6 & 92.1 \\
\hline
\end{tabular}

Reaction conditions: (1) $15 \mathrm{~g} \mathrm{EWS}, 1.0 \mathrm{wt} \% \mathrm{H}_{2} \mathrm{SO}_{4}, 150^{\circ} \mathrm{C}$ for $6 \mathrm{~h}$ in the mixture of 1,4-dioxane $/ \mathrm{H}_{2} \mathrm{O}(2: 1, \mathrm{v} / \mathrm{v}) ;(2) 180^{\circ} \mathrm{C}$ for $2.5 \mathrm{~h}$

a Total $\mathrm{H}_{2} \mathrm{SO}_{4}$ concentration at the second stage hydrolysis of hemicellulose and the breakage of the linkages between hemicellulose and lignin. The yield of lignin was enhanced from 14.1 to $17.4 \%$ as $\mathrm{H}_{2} \mathrm{SO}_{4}$ concentration was increased from 1.0 to $1.5 \mathrm{wt} \%$, and the recovery rate of lignin reached $86.6 \%$. Both the yield and purity of lignin obviously decreased with further increase in $\mathrm{H}_{2} \mathrm{SO}_{4}$ concentration. The yield of lignin decreased to $14.7 \%$ with $1.75 \mathrm{wt} \% \mathrm{H}_{2} \mathrm{SO}_{4}$, and lower lignin purity at $86.8 \mathrm{wt} \%$ was also observed (entry 4 ). The reaction temperature was varied in the range from 160 to $190{ }^{\circ} \mathrm{C}$ (entries 1, 5-7). The yield of lignin increased first but then decreased with increase in temperature. A negative effect was observed both in the yield and purity of lignin once the temperature exceeded $180^{\circ} \mathrm{C}$. Only $13.7 \%$ lignin yield was obtained at $190{ }^{\circ} \mathrm{C}$ (entry 7). The drop in the yield and purity of lignin was possibly attributed to the formation of ingoligomers derived from the degradation of lignin at higher acid concentration and temperature.

The dependence of lignin yield on the reaction time was also investigated. The yield of lignin slightly increased with increase in reaction time (entries 8,9 ). It then almost remained constant with further increase in reaction time (entries 1, 9, 10). Compared with the one-stage process, the effect of reaction time on lignin yield was less significant in the two-stage process. In the one-stage process, lignin yields at 13.5 and $14.6 \%$ were obtained for 2.5 and $6 \mathrm{~h}$ (Table 4, entries 8, 9), respectively. In the two-stage process, lignin yield was slightly improved from 17.2 to $17.6 \%$ when the reaction time was extended from 1.5 to $6 \mathrm{~h}$ (entries 1,10). These results showed that hemicellulose and lignin tend to be easily separated once hemicellulose and lignin entered the residual liquid. Thus, the reaction time had a negligible impact.

\section{Analysis of residual liquid}

Sugars in the residual liquid of the selected experiments were analyzed by HPLC [44]. The results in Table 7 revealed that xylose, mannose, arabinose, galactose and glucose were detected in the residual liquid obtained at $150{ }^{\circ} \mathrm{C}$ for $6 \mathrm{~h}$ with $0.5 \mathrm{wt} \% \mathrm{H}_{2} \mathrm{SO}_{4}$ in the mixture of 1,4-dioxane and $\mathrm{H}_{2} \mathrm{O}(2: 1, \mathrm{v} / \mathrm{v})$. Although xylose was observed to be the primary product, which must be derived from the hydrolysis of hemicellulose,

Table 7 Chemical composition of residual liquid

\begin{tabular}{|c|c|c|c|c|c|c|c|}
\hline \multirow[t]{2}{*}{ Entry } & \multicolumn{2}{|c|}{$\mathrm{H}_{2} \mathrm{SO}_{4}$ concentration (wt\%) } & \multicolumn{5}{|l|}{ Sugar } \\
\hline & First stage & Second stage & Xylose & Mannose & Arabinose & Galactose & Glucose \\
\hline 1 & 0.5 & / & ++ & + & + & Trace & Trace \\
\hline 2 & 0.5 & 1.5 & +++ & ++ & ++ & + & Trace \\
\hline
\end{tabular}

Reaction conditions: (1) $150{ }^{\circ} \mathrm{C}$ for $6 \mathrm{~h}$ in 1,4-dioxane/ $\mathrm{H}_{2} \mathrm{O}(2: 1, \mathrm{v} / \mathrm{v}) ;(2) 180^{\circ} \mathrm{C}$ for $2.5 \mathrm{~h}$

a + : Detected 
the amount of sugar produced was considerably less. It has been reported that the hydrolysis of hemicellulose produces furfural and oligosaccharide besides monosaccharide [18]. However, almost no furfural was detected in the liquor. Therefore, we speculate that hemicellulose was primarily transformed into a large number of oligosaccharides such as xylooligosaccharides, arabinooligosaccharides and mannooligosaccharides. Factually, the formation of a large number of substances with a molecular weight of $>300 \mathrm{Da}$ was detected by HPLCMS (see Additional file 1: Fig. S4). The oligosaccharides derived from hemicellulose possibly still connect with lignin via a covalent bond, which led to difficulty in the precipitation of lignin. As expected, the production of sugars was improved with increase in acid concentration and temperature, and the hydrolysis of hemicellulose was enhanced using the two-stage process. Undoubtedly, the improvement in the hydrolysis of hemicellulose was beneficial to separating hemicellulose and lignin. Therefore, higher lignin yield was observed (Table 6 , entry 1 ). The dependence of lignin yield on the hydrolysis of hemicellulose confirmed that a covalent bond may exist between lignin and the insufficient hydrolysis product derived from hemicellulose.

\section{Investigation on chemical conversion of cellulose and lignin isolated from wheat straw}

The results in Tables 5, 6 and 7 indicated that both of cellulose and lignin were well isolated from wheat straw by the two-step process. The purity of cellulose and lignin reached 86.8 and $93.2 \mathrm{wt} \%$, respectively. The chemical conversion of these two isolated constituents was further investigated to evaluate their convertible property. The catalytic conversion of cellulose into HMF and glucose was performed first in the presence of phosphotungstic acid [4]. The results in Table 8 revealed that the yields of glucose and HMF at 30.9 and $51.6 \%$ were obtained,

Table 8 The catalytic conversion of cellulose and lignin from wheat straw

\begin{tabular}{lllll}
\hline Entry & Substrate & $\begin{array}{l}\text { Yield } \\
\text { of HMF } \\
(\%)\end{array}$ & $\begin{array}{l}\text { Yield } \\
\text { of glucose } \\
(\%)\end{array}$ & Total yield (\%) \\
\hline 1 & Wheat straw cellulose & 30.9 & 51.6 & 82.5 \\
$2^{c}$ & Commercial cellulose & 33.8 & 58.2 & 92.0 \\
3 & Wheat straw lignin & $/$ & $/$ & 18.3 \\
4 & Dealkaline lignin & $/$ & $/$ & 12.6 \\
\hline
\end{tabular}

a Yield = product mass/substrate mass

${ }^{b}$ The sum of the yields of glucose and HMF for the conversion of wheat straw cellulose, and the sum of the yields of all detected monophenolic compounds for the conversion of wheat straw lignin

c Ref. [5] respectively. As a result, $82.5 \%$ total yield of glucose and HMF was obtained (entry 1 ). It has been reported that 38.8 and $58.2 \%$ yields of glucose and HMF were achieved using commercial cellulose as substrate (entry 2) [4]. The total yield reached $92.0 \%$, which was slightly higher than that derived from cellulose isolated from wheat straw. However, almost no difference was observed once cellulose purity at $86.8 \mathrm{wt} \%$ was taken into account. These results indicated that the purity of cellulose isolated from wheat straw displayed insignificant influence on the conversion. It could be ascribed to effective separation of cellulose from hemicellulose and lignin, which is helpful to destroy the interaction between components and thus favored the conversion.

The oxidative conversion of lignin isolated from wheat straw was further performed using $\mathrm{NaOH} / \mathrm{NaAlO}_{2}$ as composite catalyst. The formation of monophenolic compounds including syringaldehyde, vanillin, $p$-hydroxybenzaldehyde, acetosyringone, acetovanillone, syringic acid and vanillic acid was detected. The total yield of these monophenolic compounds reached 18.3\% (entry 3). It is well-known that dealkaline lignin is the most common and available since extensive pulp and paper production via alkali papermaking worldwide. Therefore, the oxidation of commercial dealkaline lignin was also investigated herein for comparison (entry 4). The results in Table 8 indicated that $12.6 \%$ total yield of monophenolic compounds was given, which was much lower than that of lignin isolated from wheat straw. Moreover, quantitative analysis revealed that aromatic aldehydes were the predominant products whether for the conversion of wheat straw or dealkaline lignin. However, obvious difference in product composition and species was observed. The products derived from $G$ units played the main role for the oxidation of dealkaline lignin, vanillin was the main product and $7.9 \%$ yield was achieved. However, the derivatives from $\mathrm{S}$ and $\mathrm{G}$ units were found to be the main products for the conversion of wheat straw lignin. The yields of syringaldehyde and vanillin were close, giving 6.3 and $5.8 \%$, respectively.

\section{Supplementary Information}

The online version contains supplementary material available at https://doi. org/10.1186/s13765-020-00579-x.

Additional file 1. IR spectra of EWS and lignin isolated from wheat straw under various conditions are shown. Molecular weight, ${ }^{1} \mathrm{H}$ NMR and ${ }^{13} \mathrm{C}$ NMR spectra of lignin, HPLC-MS of residual liquid are also described.

\section{Acknowledgements}

Authors extend their appreciation to Wuhan Science and Technology Bureau for supporting this work through Applied Basic Research Programs (2020020601012263), Science and Technology Department of Hubei Province for supporting this work through Important Project of Technological 
Innovation (2018ABA094) and Special Projects of Central Government in Guidance of Local Science and Technology Development (2019ZYYD059).

\section{Author's contributions}

$\mathrm{BY}, \mathrm{GF}$ and GS contributed to design, data acquisition, and analysis of the study. BY, SZ, LY and QH performed experiments. BY, GF and QC analyzed the data. JY and BC contributed to characterization. All authors read and approved the final manuscript.

\section{Funding}

This work was supported by Applied Basic Research Programs (2020020601012263) of Wuhan Science and Technology Bureau, Important Project of Technological Innovation (2018ABA094) and Special Projects of Central Government in Guidance of Local Science and Technology Development (2019ZYYD059) of Science and Technology Department of Hubei Province.

\section{Availability of data and material}

All data generated or analyzed during this study are included in this published article and its supplementary material.

\section{Competing interests}

The authors declare that they have no competing interests.

Received: 26 May 2020 Accepted: 4 December 2020

Published online: 23 January 2021

\section{References}

1. Yousefi H, Azari V, Khazaeian A (2018) Direct mechanical production of wood nanofibers from raw wood microparticles with no chemical treatment. Ind Crop Prod 115:26-31

2. Wu S, Shen D, Hu J, Zhang H, Xiao R (2016) Role of $\beta-O-4$ glycosidic bond on thermal degradation of cellulose. J Anal Appl Pyrol 119:147-156

3. Kobayashi H, Yabushita M, Komanoya T, Hara K, Fujita I, Fukuoka A (2013) High-yielding one-pot synthesis of glucose from cellulose using simple activated carbons and trace hydrochloric acid. ACS Catal 3:581-587

4. Fan G, Wang Y, Hu Z, Yan J, Li J, Song G (2018) Synthesis of 5-hydroxymethyl furfural from cellulose via a two-step process in polar aprotic solvent. Carbohyd Polym 200:529-535

5. Galebach P, Mcclelland DJ, Eagan NM, Wittrig AM, Buchanan JS, Dumesic JA, Gasser CA, Hommes G, Schäffer A, Corvini PFX (2012) Multi-catalysis reactions: new prospects and challenges of biotechnology to valorize lignin. Appl Microbiol Biot 95:1115-1134

6. Kawamoto H, Murayama M, Saka S (2003) Pyrolysis behavior of levoglucosan as an intermediate in cellulose pyrolysis: polymerization into polysaccharide as a key reaction to carbonized product formation. J Wood Sci 49:469-473

7. Poornejad N, Karimi K, Behzad T (2013) Improvement of saccharification and ethanol production from rice straw by $\mathrm{NMO}$ and [BMIM][OAC] pretreatments. Ind Crop Prod 41:408-413

8. Lu P, Hsieh YL (2012) Preparation and characterization of cellulose nanocrystals from rice straw. Carbohyd Polym 87:564-573

9. Theng D, Mansouri NEEl, Arbat G, Ngo B, Delgado-Aguilar M, Serra P, Àngels Pèlach M, Fullana-i-Palmer P, Mutjé P (2017) Fiberboards made from corn stalk thermomechanical pulp and kraft lignin as a green adhesive. Bio Resources 12:2379-2393

10. Tsegaye B, Balomajumder C, Roy P (2020) Organosolv pretreatments of rice straw followed by microbial hydrolysis for efficient biofuel production. Renew Energy 148:923-934

11. Wang Y, Hu Z, Fan G, Yan J, Song G, Li J (2019) Catalytic conversion of glucose to 5-(hydroxymethyl) furfural over phosphotungstic acid supported on $\mathrm{SiO}_{2}$-coated $\mathrm{Fe}_{3} \mathrm{O}_{4}$. Waste Biomass Valori 10:2263-2271

12. Fan GZ, Liao CJ, Fang T, Luo SS, Song GS (2014) Amberlyst 15 as a new and reusable catalyst for the conversion of cellulose into cellulose acetate. Carbohyd Polym 112:203-209

13. Dai J, Patti A, Saito K (2019) Recent developments in chemical degradation of lignin: catalytic oxidation and ionic liquids. Tetrahedron Lett 2016:4945-4951
14. Luo KH, Zhao SJ, Fan GZ, Cheng QP, Chai B, Song GS (2020) Oxidative conversion of lignin isolated from wheat straw into aromatic compoundcatalyzed by $\mathrm{NaOH} / \mathrm{NaAlO}_{2}$. Food Sci Nutr 8:3504-3514

15. Jiang $M$, Zhao M, Zhou Z, Huang $T$, Chen X, Wang $Y$ (2011) Isolation of cellulose with ionic liquid from steam exploded rice straw. Ind Crop Prod 33:734-738

16. Yan L, Ma R, Li L, Fu J (2016) Hot water pretreatment of lignocellulosic biomass: an effective and environmentally friendly approach to enhance biofuel production. Chem Eng Technol 39:1759-1770

17. Dungani R, Owolabi AF, Saurabh CK, Khalil HPSA, Tahir PM, Hazwan CICM, Ajijolakewu KA, Masri MM, Rosamah E, Aditiawati P (2017) Preparation and fundamental characterization of cellulose nanocrystal from oil palm fronds biomass. J Polym Environ 25:692-700

18. Wildschut J, Smit AT, Reith JH, Huijgen WJJ (2013) Ethanol-based organosolv fractionation of wheat straw for the production of lignin and enzymatically digestible cellulose. Bioresource Technol 135:58-66

19. Gosselink RJA, Teunissen W, Van Dam JEG, De Jong E, Gellerstedt G, Scott EL, Sanders JPM (2012) Lignin depolymerisation in supercritical carbon dioxide/acetone/water fluid for the production of aromatic chemicals. Bioresource Technol 106:173-177

20. Moniz P, Serralheiro C, Matos CT, Boeriu CG, Frissen AE, Duarte LC, Roseiroa LB, Pereirac H, Carvalheiro F (2018) Membrane separation and characterisation of lignin and its derived products obtained by a mild ethanol organosolv treatment of rice straw. Process Biochem 65:136-145

21. Mes-Hartree M, Dale BE, Craig WK (1988) Comparison of steam and ammonia pretreatment for enzymatic hydrolysis of cellulose. Appl Microbiol Biot 29:462-468

22. An S, Li W, Liu Q, Li M, Ma Q, Ma L, Chang H (2017) A two-stage pretreatment using acidic dioxane followed by dilute hydrochloric acid on sugar production from corn stover. RSC Adv 7:32452-32460

23. Zu S, Li W, Zhang M, Li Z, Wang Z, Jameel H, Chang H (2014) Pretreatment of corn stover for sugar production using dilute hydrochloric acid followed by lime. Biortech 152:364-370

24. Lawther JM, Sun RC, Banks WB (1996) Characterization of dissolved lignins in two-stage organosolv delignification of wheat straw. J Wood Chem Technol 16:439-457

25. Kim D, Lee B, Lee J, Kang P, Jeun J (2014) Electron beam irradiation and dilute alkali pretreatment for improving saccharification of rice straw. J Korean Soc Appl Biol Chem 57:591-595

26. Fan G, Wang M, Liao C, Fang T, Li J, Zhou R (2013) Isolation of cellulose from rice straw and its conversion into cellulose acetate catalyzed by phosphotungstic acid. Carbohyd Polym 94:71-76

27. Chen X, Yu J, Zhang Z, Lu C (2011) Study on structure and thermal stability properties of cellulose fibers from rice straw. Carbohyd Polym 85:245-250

28. Gonçalves C, Rodriguez-Jasso RM, Gomes N, Teixeira JA, Belo I (2010) Adaptation of dinitrosalicylic acid method to microtiter plates. Anal Methods 2:2046-2048

29. Pan $X$, Sano Y (2005) Fractionation of wheat straw by atmospheric acetic acid process. Bioresource Technol 96:1256-1263

30. Li J, Xu L, Yang B, Wang H, Bao Z, Pan W, Li S (2015) Facile synthesis of functionalized ionic surfactant templatedmesoporous silica for incorporation of poorly water-soluble drug. Int J Pharmaceut 492:191-198

31. Cheng Q, Xu C, Huang W, Ma C, Fan G, Yan J, Zhang J, Zhang Y, Song G (2020) Preparing high purity white carbon black from rice husk. Food Sci Nutr 8:575-583

32. Liu L, Li Z, Hou W, Shen H (2018) Direct conversion of lignocellulose to levulinic acid catalyzed by ionic liquid. Carbohyd Polym 181:778-784

33. Cerqueira DA, Valente AJM, Filho GR, Burrows HD (2009) Synthesis and properties of polyaniline-cellulose acetate blends: the use of sugarcane bagasse waste and the effect of the substitution degree. Carbohydr Polym 78:402-408

34. Park SJ, Jang YS (2003) Preparation and characterization of activated carbon fibers supported with silver metal for antibacterial behavior. J Colloid Interf Sci 261:238-243

35. Beltrame KK, Cazetta AL, De Souza PSC, Spessato L, Silva TL, Almeida VC (2018) Adsorption of caffeine on mesoporous activated carbon fibers prepared from pineapple plant leaves. Ecotox Environ Safe 147:64-71

36. Cazetta AL, Martins AC, Pezoti O, Bedin KC, Beltrame KK, Asefa T, Almeida VC (2016) Synthesis and application of N-S-doped mesoporous carbon 
obtained from nanocasting method using bone char as heteroatom precursor and template. Chem Eng 300:54-63

37. Wu C, Qian W, Li X, Zhu X, Xu K, Zhao Y, Dacresa OD, Hu Z, Luo G, Liu $H$, Hua H, Yao H (2019) Preparation of carbon nanofiber with specific features by degradative solvent extraction product from biomass wastes. Fuel 258:116149-116155

38. Shukla PR, Wang S (2010) Activated carbon supported cobalt catalysts for advanced oxidation of organic contaminants in aqueous solution. Appl Catal B-Environ 100:529-534

39. Ren L, Qiu Z, Wang Z, Yang D, Zhou D, Zhang T (2019) Preparation of biomass carbon/polyurethane foams for selective oil/water absorption. J Disper Sci Technol 41:1872-1878

40. Hwang KJ, Park JY, Kim YJ, Kim G, Choi C, Jin S, Kim N, Lee JW, Shim WG (2015) Adsorption behavior of dyestuffs on hollow activated carbon fiber from biomass. Sep Sci Technol 50:1757-1767

41. Acquet G, Pollet B, Lapierre C (1995) New ether-linked ferulic acidconiferyl alcohol dimers identified in grass straws. J Agr Food Chem 43:2746-2751
42. Huijgen WJJ, Reith JH, DenUil H (2010) Pretreatment and fractionation of wheat straw by an acetone-based organosolv process. Ind Eng Chem Res 49:10132-10140

43. Choi JH, Jang SK, Kim JH, Park SY, Kim JC, Jeong H, Kim HY, Choi IG (2019) Simultaneous production of glucose, furfural, and ethanol organosolv lignin for total utilization of high recalcitrant biomass by organosolv pretreatment. Renew Energ 130:952-960

44. Jin Q, Zhang H, Yan L, Qu L, Huang H (2011) Kinetic characterization for hemicellulose hydrolysis of corn stover in a dilute acid cycle spray flowthrough reactor at moderate conditions. Biomass Bioenerg 35:4158-4164

\section{Publisher's Note}

Springer Nature remains neutral with regard to jurisdictional claims in published maps and institutional affiliations.

\section{Submit your manuscript to a SpringerOpen ${ }^{\circ}$ journal and benefit from:}

- Convenient online submission

- Rigorous peer review

- Open access: articles freely available online

- High visibility within the field

- Retaining the copyright to your article

Submit your next manuscript at $\boldsymbol{\nabla}$ springeropen.com 